\title{
A CLINICAL AND HISTOPATHOLOGICAL INTERPRETATION OF LESIONS OF TUMOURS OF HINDGUT
}

\author{
Sumit Gupta1, Veena Saxena², Pragya Gupta ${ }^{3}$, Krishna Dubey ${ }^{4}$ \\ ${ }^{1}$ Assistant Professor, Department of Pathology, NIMS Medical College, Jaipur. \\ 2Professor \& HOD, Department of Pathology, NIMS Medical College, Jaipur. \\ ${ }^{3}$ Ex-Junior Resident, Department of Pathology, NIMS Medical College, Jaipur. \\ 4Junior Resident, Department of Pathology, NIMS Medical College, Jaipur.
}

\section{ABSTRACT}

\begin{abstract}
We evaluated clinical and histopathological assessments of lesions of hindgut in our hospital.
\section{METHODS}

All biopsies from surgically resected specimens of lower GIT tumors were included. Brief clinical history along with clinical findings was noted when the specimen was received. The specimen was then dissected and the gross features of the tumor were described. Standardized tissue bits were sampled from the tumor, surgical margins and lymph nodes if present.
\end{abstract}

\section{RESULTS}

The most common symptom was bleeding per rectum, weakness, pain abdomen and constipation in the order $87 \%, 82 \%, 68 \%$, $61.5 \%$ respectively. The commonest gross morphological features of neoplasms of lower GIT was ulceroproliferative growth $129 / 200$ (64.5\%) followed by polyp 71/200 (35.5\%). The commonest location was anorectosigmoid region, colon, jejunum, ileum (48\%, 39.5\%, 7\%, 5.5\%) respectively. In resected specimens only $28(14 \%)$ specimens showed lymph nodal metastasis and the commonest histological type was well differentiated adenocarcinoma (29\%).

\section{CONCLUSION}

Hindgut lesions exhibited a wide spectrum of histopathological features, adenomatous polyp and well differentiated adenocarcinoma being most common among benign and malignant lesions.

\section{KEYWORDS}

Benign, Malignant, Adenocarcinoma, Polyps, Hindgut Tumors.

HOW TO CITE THIS ARTICLE: Gupta S, Saxena V, Gupta P, et al. A clinical and histopathological interpretation of lesions of tumours of hindgut. J. Evolution Med. Dent. Sci. 2016;5(14):643-646, DOI: 10.14260/jemds/2016/148

\section{INTRODUCTION}

The large bowel is the leading site for cancers in developed countries comparatively small bowel throughout the worldwide.[1] The colorectal cancers are the third most common cancers and the third leading cause of cancer related death in both males and females, which constitute $10 \%$ of all cancers. ${ }^{[2,3]}$ In Indian population, it is the 10th most common cancer and constitutes $4 \%$ of cancer deaths. ${ }^{[4,5,6]}$ The geographical variation is attributed to differences in diet, particularly consumption of red and processed meat, fiber, alcohol, body weight and physical activity.[7,8]

Endocrine tumours are the next most common tumours of midgut with duodenal tumours amounting to $22 \%$ of all gastrointestinal endocrine neoplasms.[2] whereas the jejunoileal tumours account $23-28 \%$ of all gastrointestinal endocrine tumours making this the second most common site for endocrine tumours following appendix.9,10 We evaluated the histopathological features of lower GI tract lesions in relation with clinical correlation of the lesions in patients visiting a tertiary care hospital.

\section{METHODS}

The prospective histopathological evaluation was conducted between 2014 and 2015 in the Department of Pathology, N.I.M.S. Medical College, Jaipur.

Financial or Other, Competing Interest: None.

Submission 28-12-2015, Peer Review 28-01-2016,

Acceptance 03-02-2016, Published 17-02-2016.

Corresponding Author:

Dr. Sumit Gupta,

B-24, Ganesh Nagar, Moti-Doongri,

Jaipur-302004, Rajasthan.

E-mail: drsumitpatho@yahoo.com

DOI: $10.14260 /$ jemds $/ 2016 / 148$
All biopsies from surgically resected specimens of lower GIT tumors were included. Brief clinical history along with clinical findings was noted when the specimen was received. The specimen was then dissected and the gross feature of the tumor was described. Standardized tissue bits were sampled from the tumor, surgical margins and lymph nodes if present. The biopsy material either from endoscopic biopsies or from dissected tumors was kept in $10 \%$ formalin for $12-36$ hours to allow rapid fixation without shrinkage. The fixed biopsy material was wrapped in a piece of filter paper and processed in a perforated cassette. After processing, the biopsies were unwrapped and embedded in paraffin with mucosal surface perpendicular to the cutting surface; 4 to $5 \mu$ thick sections were cut and about 5-6 sections were taken on each slide, stained with Hematoxylin and Eosin ( $\mathrm{H}$ and $\mathrm{E}$ ) and studied. Special stains like (Giemsa) were used wherever necessary. Correlation of clinical, endoscopic findings and histopathological findings was done.

\section{STATISTICAL ANALYSIS}

Data was entered into Excel Spread Sheet 2007. Data was then cleaned, mined and extracted using if and sort functions. Data was described as actual numbers and percentages for categorical variables and Mean and SD for continuous variables. Generation of Pivotal tables and Statistical analysis was performed by using Microsoft Excel spreadsheet only.

\section{RESULTS}

The most common symptom was bleeding per rectum, weakness, pain abdomen and constipation in the order $87 \%$, $82 \%, 68 \%, 61.5 \%$ respectively (Table 1 ). 
The commonest gross morphological features of neoplasms of lower GIT was ulceroproliferative growth $129 / 200$ (64.5\%) followed by polyp 71/200 (35.5\%). The commonest location was anorectosigmoid region, colon, jejunum, ileum $(48 \%, 39.5 \%, 7 \%, 5.5 \%)$ respectively. Resected specimens only $28(14 \%)$ specimens showed lymph nodal metastasis and the commonest histological type was well differentiated adenocarcinoma (29\%) (Table 2).

\begin{tabular}{|c|c|c|}
\hline Clinical Symptom & $\begin{array}{c}\text { Number of } \\
\text { Cases }\end{array}$ & $\mathbf{\%}$ \\
\hline Rectal bleeding & 174 & 87 \\
\hline Constipation & 123 & 61.5 \\
\hline Pain abdomen & 136 & 68 \\
\hline Weakness & 164 & 82 \\
\hline \multicolumn{2}{|c|}{ Table 1: Clinical symptoms } \\
in tumors from Hindgut
\end{tabular}

The most common symptom was bleeding per rectum presenting in 87 percent of patients followed by weakness in $82 \%$ of patients, pain abdomen in $68 \%$ of patients and constipation in $61.5 \%$ of patients.

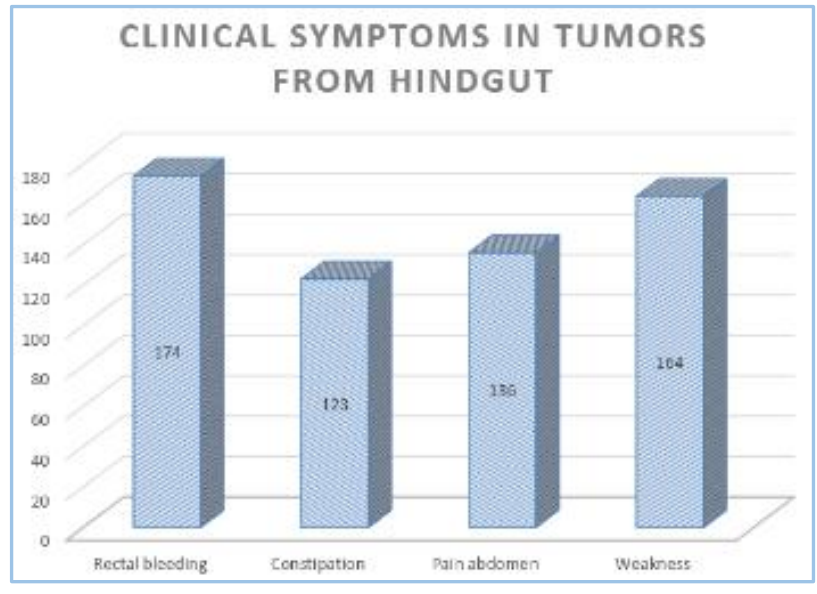

Graph 1: Showing distribution of clinical symptoms

\begin{tabular}{|c|c|c|c|c|c|c|}
\hline Histopathology & Ileum & Jejunum & Colon & Anorectal Sigmoid & Total & $\%$ \\
\hline \multicolumn{7}{|c|}{ Benign } \\
\hline Adenomatous polyp & 0 & 0 & 6 & 12 & 18 & 9 \\
\hline Hyperplastic polyp & 0 & 0 & 8 & 8 & 16 & 8 \\
\hline Hyperplastic polyp with atypical changes & 0 & 0 & 5 & 0 & 5 & 2.5 \\
\hline Inflammatory polyp & 0 & 0 & 3 & 6 & 9 & 4.5 \\
\hline Juvenile polyp & 0 & 0 & 0 & 12 & 12 & 6 \\
\hline Lipomatous Polyp & 0 & 0 & 11 & 0 & 11 & 5.5 \\
\hline \multicolumn{7}{|c|}{ Malignant } \\
\hline Squamous papilloma & 0 & 0 & 0 & 6 & 6 & 3 \\
\hline Malignant carcinoid in multiple sites & 0 & 5 & 0 & 0 & 5 & 2.5 \\
\hline Neuroendocrine Tumor & 0 & 0 & 0 & 6 & 6 & 3 \\
\hline Non-Hodgkin's lymphoma & 6 & 4 & 0 & 0 & 10 & 5 \\
\hline Well differentiated adenocarcinoma & 0 & 5 & 21 & 32 & 58 & 29 \\
\hline Moderately differentiated adenocarcinoma & 0 & 0 & 6 & 6 & 12 & 6 \\
\hline Poorly differentiated adenocarcinoma & 5 & 0 & 7 & 0 & 12 & 6 \\
\hline Mucinous adenocarcinoma & 0 & 0 & 8 & 8 & 16 & 8 \\
\hline Signet ring cell adenocarcinoma & 0 & 0 & 4 & 0 & 4 & 2 \\
\hline Grand Total & 11 & 14 & 79 & 96 & 200 & 100 \\
\hline \multicolumn{7}{|c|}{ Table 2: Site distribution and Histopathological Variants } \\
\hline
\end{tabular}

The commonest location was anorectosigmoid region in $48 \%$ of patients, colon in $39.5 \%$ of patients, jejunum in $7 \%$ of patients and ileum in $5.5 \%$ of patients $(48 \%, 39.5 \%, 7 \%, 5.5 \%)$ respectively.

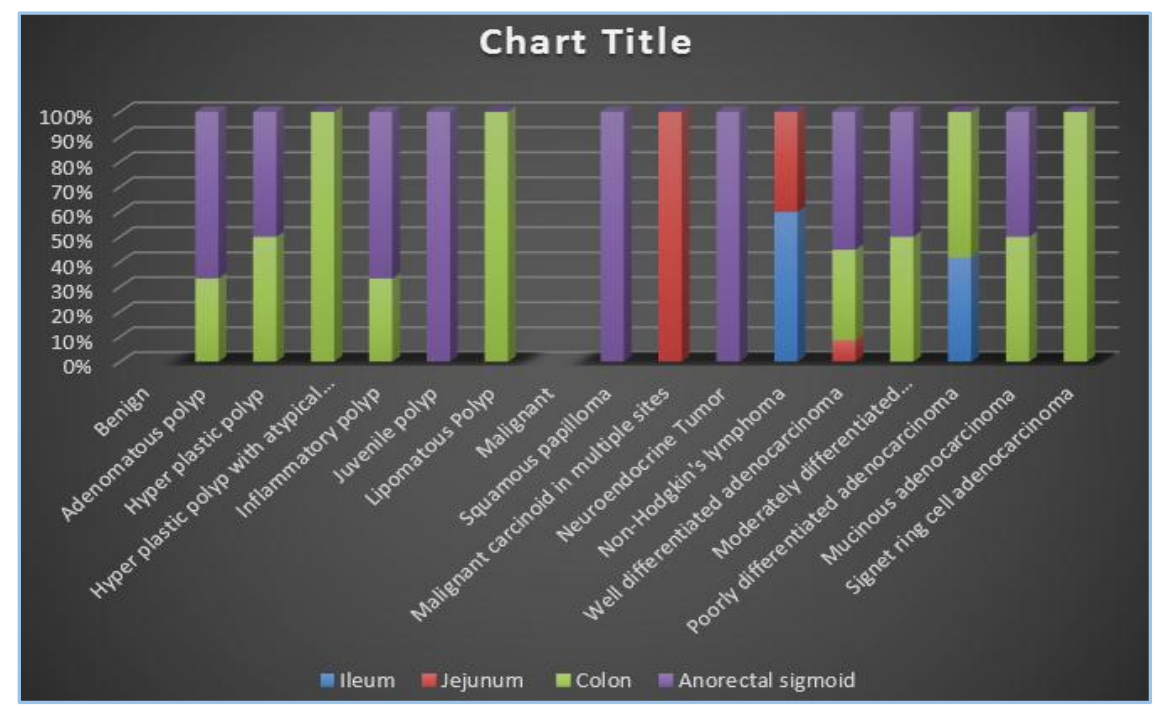

Graph 2: Site distribution and Histopathological Variants 


\section{DISCUSSION}

All the specimens of hindgut (Large intestine and anal canal) tumours submitted in Department of Pathology were analysed by light microscopic findings with special emphasis on the histological type and grade of tumours.[11]

Rudy DR, Zdon MJ, et al. [12] found tubular adenoma was the most common benign tumour (83\%) of all the benign tumours, whereas in our study it was adenomatous polyp (9\%). Adenocarcinoma (29\%) was the most common malignant tumour in our study. In the study by Rosai J, Ackerman and Kumar $\mathrm{V}$ et al.[13,14) adenocarcinomas were found in $70 \%$ of the cases.

Colorectal Cancer (CRC) is the third most cancer in men $(10 \%$ of total cancers) and the second in women $(9.4 \%$ of the total cancers) worldwide and lowest in Africa and SouthCentral Asia, but still the age adjusted rates of CRC in Indian registries are very close to the lowest rates in the world. $[2,3]$

\section{CONCLUSION}

Hindgut lesions exhibited a wide spectrum of histopathological features, adenomatous polyp and well differentiated adenocarcinoma being most common among benign and malignant lesions.

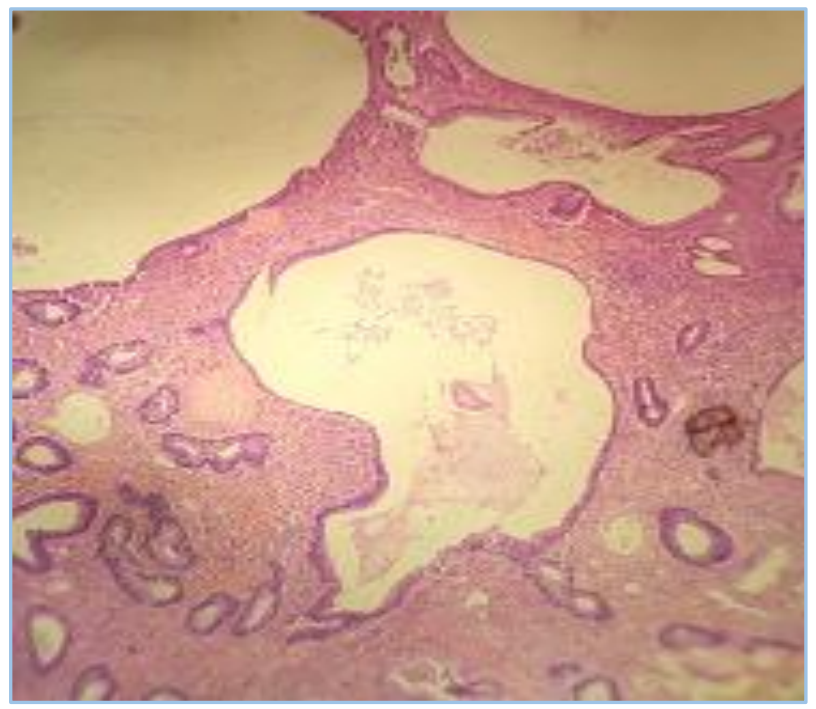

Image A: Juvenile Polyp

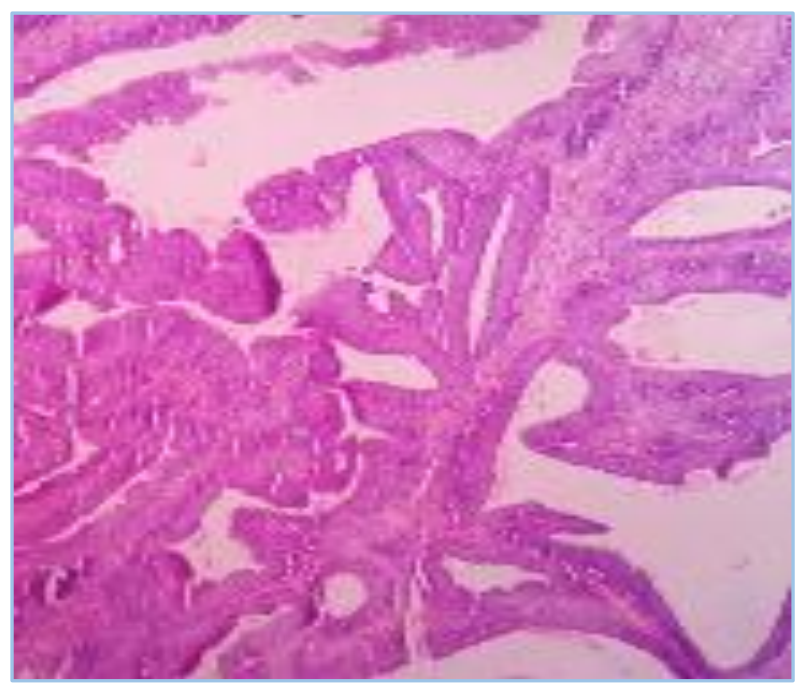

Image B: Moderately Differentiated Adenocarcinoma

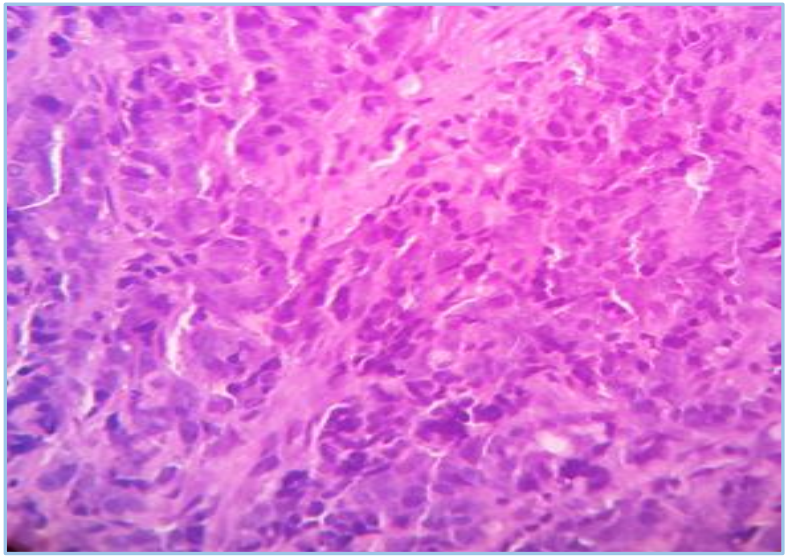

Image C: Poorly Differentiated Adenocarcinoma

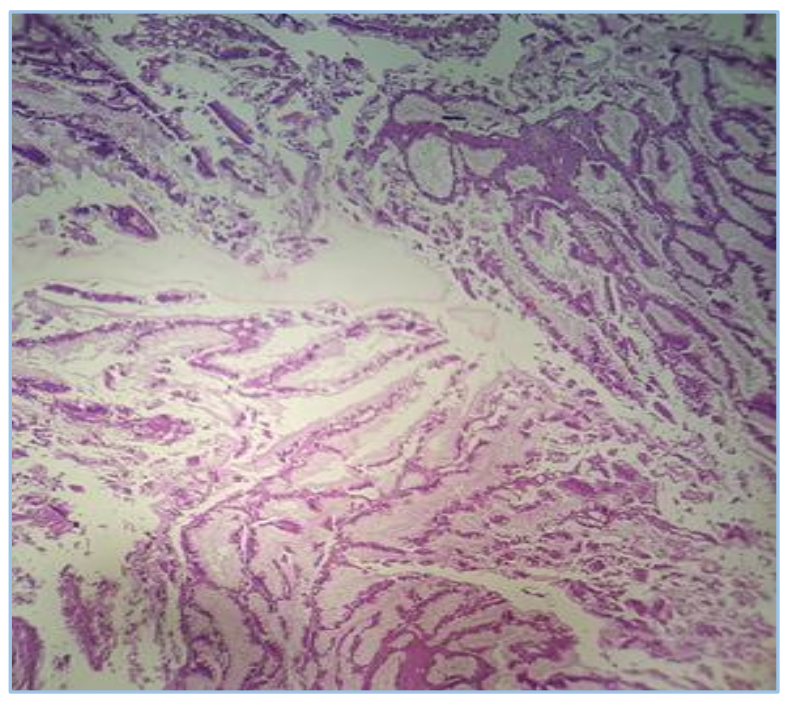

Image D: Mucinous Adenocarcinoma

\section{REFERENCES}

1. Mohandas KM1, Desai DC. Epidemiology of digestive tract cancers in India. V. Large and small bowel. Indian J Gastroenterol 1999 Jul-Sep;18(3):118-21.

2. Jemal A, Bray F, Center MM, et al. Global cancer statistics. CA Cancer J Clin 2011;61:69-90.

3. Kamangar F, Dores GM, Anderson WF. Patterns of cancer incidence, mortality and prevalence across five continents: defining priorities to reduce cancer disparities in different geographic regions of the world. J Clin Oncol 2006;24: 2137-2150.

4. Sankaranarayanan R, Black RJ, Parkin DM. Cancer survival in developing countries. Lyon (France): IARC Scientific Publications, No. 145; 1999.

5. Sankaranarayanan R, Swaminathan R, Brenner $\mathrm{H}$, et al. Cancer survival in Africa, Asia and Central America: a population-based study. Lancet Oncol 2009;11:110-111.

6. Coleman MP, Quaresma M, Berrino F, et al. Cancer survival in five continents: a worldwide population-based study (CONCORD). Lancet Oncol 2008;9:730-756.

7. Alexander DD, Cushing CA. Red meat and colorectal cancer: a critical summary of prospective epidemiologic studies. Obes Rev 2011 May;12(5):e472-93. doi:10.1111/j.1467789X.2010.00785.x. Review. PubMed PMID: 20663065. 
8. Br J Cancer 2011 Jan 4; 104(1):6-11.

Doi: 10.1038/sj.bjc.6606032. Epub 2010 Nov 30. Review. PMID:21119663.

9. Goldwin JD (1975). Carcinoid tumours. An analysis of 2387 cases. Cancer 36:560-569.10

10. Vinik AL, McLeod MK, et al. (1989). Clinical features, diagnosis and localization of carcinoid tumours and their management. Gastroenterol Clin North Am 18:865-89611. Wright DH (1995). The major complications of coeliac disease. Baillieres Clin Gastroenterol 9:351-369.
11. Wright DH (1995). The major complications of coeliac disease. Baillieres Clin Gastroenterol 9:351-369.

12. Rudy DR, Zdon MJ. Update on colorectal cancer. Am Fam Physician 2000;61:1759-70, 1773-4.

13. Rosai J, Ackerman. Gastrointestinal tract. In surgical pathology 9th edition. St. Louis Mosby; 2004;615-870.

14. Kumar V, Abbas AK, Fausto N. The gastrointestinal tract. In: Pathologic Basis of Disease 7th ed. Elseveir Inc. 2004;797876. 